\title{
Family-centered care from the perspective of nurses in the Neonatal Intensive Care Unit
}

\author{
Cuidado centrado na família na perspectiva de enfermeiras da Unidade de Terapia Intensiva \\ Neonatal
}

Thaís Regina Gomes da Silva ${ }^{1}$, Bruna Figueiredo Manzo ${ }^{1}$, Fernanda Cristina Custodia de Faria Fioreti², Paloma Morais Silva ${ }^{1}$

Objective: to describe the challenges and strategies for implementation of Family-centered Care in the in the care of newborns hospitalized in the Intensive Care Unit from the perspective of nurses. Methods: qualitative study conducted in the Neonatal Intensive Care Unit of a public hospital. Fourteen nurses were interviewed. We used the technique of thematic content analysis. Results the main aspects hindering the implementation of Family-centered Care were: lack of material resources, absence of parents in the unit and shortage of staff, which influenced directly in the assistance provided to the newborn and the family. To minimize the challenges, nurses mentioned strategies such as creating and updating protocols, training, continuing education programs, optimizing communication and meetings with families. Conclusion: the main challenges are related to human and material resources and infrastructure. Strategies mentioned were teamwork and continuous improvement. Descriptors: Intensive Care Units, Neonatal; Neonatal Nursing; Family Nursing; Nursing Care.

Objetivo: descrever os desafios e as estratégias para implementação do Cuidado Centrado na Família no cuidado ao recém-nascido hospitalizado em Unidade de Terapia Intensiva, na perspectiva de enfermeiras. Métodos: estudo qualitativo, conduzido na Unidade de Terapia Intensiva Neonatal de uma maternidade pública. Foram realizadas entrevistas com 14 enfermeiras. Utilizou-se a técnica da análise de conteúdo temática. Resultados os principais aspectos dificultadores encontrados para implementação do Cuidado Centrado na Família foram: carência de recursos materiais, ausência dos pais na unidade e escassez de funcionários, que influenciaram diretamente na assistência ao recém-nascido e à família. Para minimizar os desafios encontrados, as enfermeiras apontaram estratégias como criação e atualização de protocolos, treinamentos, programas de educação continuada, otimização da comunicação e reuniões com as famílias. Conclusão: os principais desafios referem-se aos recursos humanos e materiais e à infraestrutura. Como estratégias, foram apontados trabalho em equipe e aperfeiçoamento constante.

Descritores: Unidades de Terapia Intensiva Neonatal; Enfermagem Neonatal; Enfermagem Familiar; Cuidados de Enfermagem.

\footnotetext{
${ }^{1}$ Universidade Federal de Minas Gerais. Belo Horizonte, MG, Brazil.

${ }^{2}$ Hospital Municipal Odilon Behrens. Belo Horizonte, MG, Brazil.

Corresponding author: Thaís Regina Gomes da Silva

Rua Santa Catarina, 94, Ingá, CEP: 32604-582. Betim, MG, Brazil. E-mail: thaisrgs@outlook.com
} 


\section{Introduction}

Family-centered Care is a care model where the family is inserted in the planning and decision-making of care along with health professionals and the patient. The family is aware of the potential benefits and risks and is granted comfort regarding the assistance given and receives the assurance of its quality ${ }^{(1-3)}$. The Institute of Medicine defines family-centered care as one of the six requirements for high quality health care. However, the non-implementation of this model, due to either ignorance or lack of interest of health professionals or inadequate infrastructure of hospitals, generates consequences that influence negatively the evolution of the comorbidity ${ }^{(1,3)}$. Familycentered care follows the principles established in the agreement between relevant institutions that guide the care practice, considering the sharing of information among all involved in the care in an impartial, clear and objective way, respecting the values and wishes of the patient and encouraging this and the family to have an active participation in the planning of treatment ${ }^{(2,4)}$.

Therefore, in family-centered care, the family is acknowledged as a partner of the team and its participation in the assistance contributes to the affective bonding between caregiver and patient, helping to reduce the stress that hospitalization and continuity of care at home after discharge causes to parents ${ }^{(1,4)}$. It is noteworthy that this model considers the family as the basic unit of care, inseparable from the patient, especially when this is a child. It is the responsibility of the health team, as a whole, to include caregivers in the caring activities, involving them effectively in the moment of planning these activities, with basis to keep them aware of their role and their importance in the group, not simply as performers of procedures providing care with focus in the biological process of the disease that affects the patient ${ }^{(4-6)}$.

It is observed that within the Neonatal Intensive Care Unit, families experience fears and anxieties. In most, expectations are denied with the birth of a baby with congenital or perinatal problems and who needs immediate intervention and/or is under risk of life, different from what was desired during pregnancy. This causes stress and worry about the future and about parental failure ${ }^{(7-8)}$.

Taking into accoutn that taking care of the family is also a responsibility and moral commitment of nursing, since nurses are directly involved in care practice, it is up to these professionals to evaluate the time to intervene in a favorable environment, along with the family to encourage the sharing of knowledge, skills and resources, making both parts to become competent partners in their assignments, and generating autonomy and power about their decisions $^{(6)}$.

As stated, research demonstrates that familycentered care in neonatology is important and beneficial because of decreased workload, greater satisfaction with the assistance, reduction of adverse events, comfort and family support at this traumatic time, and reduced length of stay ${ }^{(1,3,5)}$. Despite of it, there are few studies approaching the challenges and strategies Family-centered Care in Neonatal Intensive Care Units. A study with this aim may arise reflections on the practice of nursing, seeking changes on nursing care to newborns hospitalized and their families, and may contribute to overcoming the challenges and point to strategies of family-centered care in Neonatal Intensive Care Units, ensuring the effectiveness of the care provided.

Thus, the aim of the present study was to describe the challenges and strategies used for implementation of Family-centered Care in newborns admitted to a Neonatal Intensive Care Unit, from the perspective of nurses.

\section{Methods}

This is a qualitative study which had as scenario the Neonatal Intensive Care Unit of a public maternity hospital in Belo Horizonte, Minas Gerais, Brazil, a reference to neonatology in the state. The 
study was performed with 14 clinical nurses in the unit. As inclusion criterion, the nurse had to be working in the service for more than one year because it is believed that, with this time, nurses are aware of the organizational culture of the institution and understand the routines of the unit. Data collection was conducted through semi-structured interviews in a private room in the workplace, with an average duration of 20 minutes, during the work shift of the participants, between April and June 2014. Interviews were conducted by two authors with each participant individually and ended when data began to show redundancy or repetition ${ }^{(9-10)}$. It is noteworthy that there was no refusal from professionals to participate in the survey neither termination of participation was requested at any time.

The interview script consisted of four questions about the nursing care provided by the staff to the newborn and its family and the participation of the family in the care: What do you think about the way you have developed your work of providing care to the child and its family? How do you see the family in the context of hospitalized children? What precautions have you taken regarding the assistance and the care to the family? What are the implications of your care for the family and the hospitalized child?

With prior approval of participants, the interviews were recorded and transcribed by researchers. Subsequently, interviews were submitted to the respondents for them to validate their statements, prior to the analysis of the collected material. To assure anonymity, the speeches of each interviewee appear encoded by NUR followed by a numerical digit representing the order of participation, 1 to 14 , for example, NUR1 (Nurse 1).

Data analysis was based on content analysis, with three distinct phases: pre-analysis, material exploration and processing of results. Pre-analysis consisted of ordering data transcribed in full-length and organizing the material records into units of registration and the form of categorization. Coding, classification and aggregation of findings, which represents the second phase, comes from comes from exploring the material. Then, to complete the analysis of the data, results were treated according to the theoretical framework found ${ }^{(9-10)}$.

The study complied with the formal requirements contained in the national and international regulatory standards for research involving human beings.

\section{Results}

The 14 participants were female, aged between 25 and 45 years. Time of experience in neonatal intensive care units ranged from 2 to 6 years.

The study of the perspective of nurses about the difficulties faced while implementing Familycentered Care and the strategies identified by these professionals, the following empirical categories emerged from the analysis: Aspects that hinder the implementation of Family-centered Care and Strategies to implement of Family-centered Care.

\section{Aspects that hinder the implementation of Family- centered Care}

Nurses who work in Neonatal Intensive Care Units reported that there are several aspects hindering the implementation of practices guided by family-centered care. These include the lack of material resources, infrastructure and human resources, all influencing directly in the provision of care to the newborn and its family. The public hospital has flaws, sometimes it is the material, sometimes personnel is also missing, but find our way out in these situations, to help in patient care ... (NUR14).

Some respondents pointed out that the unit did not have adequate infrastructure, compatible with the demand to host parents in the unit with comfort and safety. The statements indicate the above: The physical structure does not help us in the matter of encouraging a true familycentered care. Sometimes the mother does not even have a place to sit, because sometimes the number of patients is beyond the capacity 
(NUR5). Here we are unable to keep the baby in respiratory isolation with the mother, for example, the baby will be in the middle of other babies (NUR14).

With regard to human resources, most of the interviewees pointed out that the shortage of staff culminated in work overload, stress, fatigue, exhaustion and anxiety in the team for failing to provide the necessary attention to the child and its family. I'm disheartened by the lack of employees, we have to assume service that is not ours, then we have to do other things that are our duty, but there is no time left (NUR13). I think sometimes we fail a little with respect to Family-centered Care, sometimes we leave it a little aside because of other activities (NUR6).

There were also references to the lack of discussion among the team members for the purpose of planning and evaluating the care to be offered to patients: I think that discussing the procedures is essential too, we do not have a moment to discuss it, ... a time for us to encourage this within the unit ... we don't have clinical meetings with the entire staff to be able to plan the activities related to that patient. At first, we managed to make a clinical meeting, but the demand was so great to work ... we could not effectively take this forward, to make the planning (NUR5).

Another point mentioned was that the presence and participation of parents in the unit has become a challenge to the professional: When the mother isinside the Intensive Care Unit for too long, this represents a challenge for the professional, because then she staying there, she is constantly questioning everything that is being done with her baby. ... With the companion at the side, actually, the demand is greater (NUR7).

It was also found that, although some professionals recognize the value of the family for the child, unpreparedness was present among the nursing staff in dealing with family: It is a feature of the health professional who wants to complete control over the care and he thinks it involves technique, when the child needs mainly that the family be involved ... but the team as a whole has this difficulty to involve the family in this care, is a flow in our nursing (NUR2).

The nurses also highlighted families that are very little participatory or absent in the unit and this is an obstacle to the effectiveness of family-centered care, as stated: I do not see much the presence of parents, they are not very present. These are parents who have a lower economic status; they depend on the bus to leave. Some mothers who are in the countryside and they are stay in a hosting house for pregnant woman, even so, I do not see their presence here in the evening, they return to the house for pregnant women at night, early in the call (NUR 3).

The findings also pointed to a lack of understanding of the family regarding the clinical situation of the child, which could influence the engagement in care: We have a lot of teenage mothers who have difficulty understanding even of the situation, understanding the need for them here (NUR 3). The lack of understanding of those who are companions, really, because often you give instructions to the person who is responsible, sometimes this person listens to you, but sometimes doesn't (NUR 11).

Furthermore, professionals reported that certain feelings and attitudes expressed by the family interfered in the practice of Family-centered Care: Certain aggressiveness, the companion already has, naturally, so sometimes he will not listen, will not let you talk, or sometimes, too much anxiety, they can not. ...Sometimes the mother has that moment of denial (NUR 11).

\section{Strategies to implement of Family-centered Care}

Nurses interviewed in this study pointed out strategies for effectively carrying out family-centered care. With regard to infrastructure, some nurses suggested improvement of the structure by increasing the space for the family, the number of beds and the amount of equipment: If we could have a better structure, mainly to keep parents $24 \mathrm{~h}$, a place where they could rest, more space and if we had a fixed number of beds ... to be able to give more attention to the family (NUR 4).

In addition, the development of new actions in the unit for proper practice of family-centered care was mentiones. These include creating and updating protocols, training and continuing education programs, preferably to include the multidisciplinary team: Training, really, with parts designed to raise awareness among the entire staff... it has to be from the medical staff to the cleaning staff, they have to be aware that we have this mentality of integrating mother and child inside the Centre of Intensive therapy. 
Furthermore, besides the work to araise awareness, training is needed really, technical training to demonstrate how to make ... (NUR3).

Part of the nurses pointed the effective communication between the team as strategy, because each area may have a different view on the clinical case and it was valid to share this view: We need to have good dialogues about it because when conversations happen, I say, even someone outside the team opens a much wider range, because sometimes we are there in a very repetitive work and cannot see certain things. So, when we have a ... meeting to dialogue or someone to come to add to another look, I think it would much easier to see what could be changed (NUR11).

Communication between staff and family was also highlighted as a strategy, exemplifying that the moment of reception should be held with the admission of the child in the unit, but that this often did not happen due to work overload: The baby came to the Neonatal Intensive Care Unit, then I do not know that baby neither the mother. So, I think that this hosting should begin at the very moment when the mother arrives at the unit ... it would be good doing this even for us decrease some problems, we can come close and, the use of the phone, such as washing hands, as I will enter the unit.... sometimes the staff is so busy, so busy with many tasks that consume time, that sometimes that mothers goes unnoticed (NUR5).

Another suggested strategy for implementation of Family-centered Care refers to the constant realization of meetings with the families in order to answer questions and bring them closer to the care and the staff, providing comfort and safety: It would be good not only for the nursing staff, but mainly for the family, weekly meetings with the mothers for us to educate them about the operation of the unit or to demystify something they might see happening. ...Therefore, this previous or recurrent information, I think it would facilitate their stay in the unit, for them do not get scared with alarms, with the procedures and for make them feel more welcomed (NUR 1).

\section{Discussion}

The limitation of the present study was it did not use other sources of information, aimed at internal reliability, as triangulation data. In addition, the research was conducted in only one institution, and thus it is not possible to generalize the findings to other settings.

It is expected that, with this study, reflections on the challenges faced in the implementation of family-centered Care be constant among health care providers and nursing professionals, so that they may plan and develop actions that result in the optimization of the existing framework. Similarly, the identified strategies should be evaluated by managers of services and serve as templates for new changes in nursing practice.

Data analysis has shown that there was a shortage in material resources, infrastructure and human resources in the Neonatal Intensive Care Unit. This delay directly influences any care provided by the health team, hindering the contemplation of the needs of the patient-family dyad. In this sense, nurses seek to adapt the structure to the need of the family and the patient, trying to minimize dissatisfaction with the service and to reduce the suffering experienced by them during hospitalization ${ }^{(11)}$.

For implementation of family-centered care, it is important the Neonatal Intensive Care Unit to have proper infrastructure to accommodate family members and to encourage their stay in this environment, what include the availability of bathrooms, dining rooms, chairs in sufficient quantity and equipment that suit the specificities of the case of each patient ${ }^{(1)}$. However, the structure itself is not enough for assuring Family-centered Care. It is necessary that professionals be aware of this and reflect on the care offered, as well as new practices and routines within the unit are necessary. Training for current care practices, demonstration of good practice manuals and continuing education for nursing staff is important in order to improve and qualify the assistance. These practices are essential to advance the Family-centered Care, and should be recurrent and continually updated, evidence-based and guided in the practice. This way they will increase the credibility of the service, contributing to adapting the findings to the service reality ${ }^{(1-2,8,12)}$. 
The findings of the present study showed that the nursing staff faces difficulties to involve families in care. A recent study showed that even when professionals recognize with the practice or new training the importance of the family in the unit, only the care that professionals deem relevant is delegated to the family, disregarding the importance of taking decisions and creating the treatment plan in a shared manner between staff and family ${ }^{(4)}$. In addition, professionals realized as a challenge the fact that some familie members make questions about the assistance. It is known that family members seek, as they experience daily life care in the Neonatal Intensive Care Unit and the interaction with the professionals who work in it, to be closer to the child's needs and acquire knowledge that allow them to evaluate and question the care offered by professionals ${ }^{(13)}$.

With respect to creating and updating protocols, these are needed because they help and direct the service practices. It is also necessary that all professionals in the institution have knowledge and receive adequate training to apply them. This way, each collaborator will know about their activities, which will be based on scientific evidence, as well as decisions to be taken regarding the therapeutic ${ }^{(1)}$.

When analyzing the challenges to the practice of family-centered care, it can be concluded that, in the absence of the family, it is impractical to direct this or pay attention to its needs. It is important to note that the aspects preventing parents to stay in the unit are issues related to work, place of residence, financial situation or other children ${ }^{(8)}$. Thus, it is necessary to expand the forms of social support through, for example, support groups and socialization of the information on services and institutions that can support the family and help this, both during hospitalization and in moments after discharge. It is also important to welcome the family, provide clear and objective information, and create a favorable environment for the resolution of doubts, since the effective interaction between staff and family is a practice that contributes to the Family-centered Care $^{(14)}$.

With regard to strategies to implement Familycentered Care, it is important that during academic training in nursing, students have access to content addressing this theme in all moments during the course, particularly in subjects of the mother-child context. Based on the discussions of this topic, nurses can graduate with the prospect of Family-centered Care and with this they will have the ability to plan actions to apply this approach to care, benefiting the patient and family ${ }^{(4)}$.

Communication is one of the principles governing the Family-centered Care. This creates rapport between the team, improving the assistance. When communication is missing, each professional covers only what is appropriate for his expertise area, making the care fragmented, and affecting the final result ${ }^{(1)}$. The lack of consistent and objective information is one of the aspects that most concerns and causes anxiety to parents, and it also limits their participation in the care of the hospitalized child. These stressful or worrying factors can be avoided or minimized with an explanation given by nurses on the procedures made and the benefits brought by them, establishing a meeting of care in which the interaction would be fully realized by means of enlightening and frank dialogue with family, seeking the meaning and significance of these health actions ${ }^{(4)}$. Still, an environment that favors the interpersonal relationship is critical to creating bonds of trust. Here, the nurse becomes an individual who provides comfort and support, allowing the practice of nursing care $^{(15-16)}$.

Finally, we highlight the importance and the need, for both the family and the health service, of the creation and expansion of opportunities for participation of the family. This should include operating groups, meetings, in which the goal should be to exchange experience and moments for reflection on the events taking place within the unit and even out 
of it. Thus, participants can transform the reality found in a more welcoming place, reducing the emotional load that the environment brings, and complying with the principles of family-centered care ${ }^{(17)}$.

\section{Conclusion}

In the study, it was found that the participating nurses did not understand the importance of practice Centered Care in the Family in its entirety, as delegated care to parents and distinguished family just like a companion that helped when it suited them, not as a participant care planning. However, it was revealed in a few speeches that there were isolated actions that inserted the family in the care, trying to adapt ways to improve this scenario within the conditions that they have, respecting the scientific principles.

It is noteworthy that the main points highlighted by the professionals as challenges and possibilities are related to the physical, human and material resources, to nurses and to the own families.

\section{Collaborations}

Manzo BF participated in the design of the project, collection, analysis and interpretation of data, writing of the article and in the approval of the final version to be published. Silva TRG contributed in the analysis and interpretation of data, writing the article and in the approval of the final version to be published. Fioreti FCCF and PM Silva contributed in the writing, critical review relevant content and approval of the final version to be published.

\section{References}

1. Dudley N, Ackerman A, Brown KM, Snow SK. Patient-and family-centered care of children in the Emergency Department. Pediatrics. 2015; 135(1):255-72.
2. Kuo DZ, Houtrow AJ, Arango P, Kuhlthau KA, Simmons JM, Neff JM. Family-centered care: current applications and future directions in pediatric health care. Matern Child Health J. 2012; 16(2):297-305.

3. Cruz AC, Angelo, M. Cuidado centrado na família em pediatria: redefinindo os relacionamentos. Cienc Cuid Saúde. 2011; 10(4):861-65.

4. Pacheco STA, Rodrigues BMRD, Dionísio MCR, Machado ACC, Coutinho KAA, Gomes APR. Cuidado centrado na família: aplicação pela enfermagem no contexto da criança hospitalizada. Rev Enferm UERJ. 2013; 21(1):106-12.

5. Lima AS, Silva VKBA, Collet N, ReichertAPS, Oliveira BRG. Relações estabelecidas pelas enfermeiras com a família durante a hospitalização infantil. Texto Contexto Enferm. 2010; 19(4):700-8.

6. Pinto JP, Ribeiro CA, Pettengill MM, Balieiro MMFG. Cuidado centrado na família e sua aplicação na enfermagem pediátrica. Rev Bras Enferm. 2010; 63(1):132-5.

7. Schmidt KT, Sassá AH, Veronez M, Higarashi IH, Marcon SS. A primeira visita ao filho internado na unidade de terapia intensiva neonatal: percepção dos pais. Esc Anna Nery. 2012; 16(1):73-81.

8. Raffray M, Semenic S, Galeano SO, Marín SCO. Barriers and facilitators to preparing families with premature infants for discharge home from the neonatal unit: Perceptions of health care providers. Invest Educ Enferm. 2014; 32(3):37992.

9. Minayo MCS. O desafio do conhecimento: pesquisa qualitativa em saúde. São Paulo: Hucitec; 2010.

10. Bardin L. Análise de conteúdo. Lisboa: Edições 70; 2012.

11. Sousa LD, Gomes GC, Silva MRS, Santos CP, Silva BT. A família na unidade de pediatria: percepções da equipe de enfermagem acerca da dimensão cuidadora. Cienc Enferm. 2011; 17(2):87-95.

12. Apolinário MICG. Cuidados centrados na família: impacto da formação e de um manual de boas práticas em pediatria. Referência. 2012; 3(7):8392. 
13. Duarte ED, Sena RR, Dittz ES, Tavares TS, Lopes AFC, Silva PM. A família no cuidado do recémnascido hospitalizado: possibilidades e desafios para a construção da integralidade. Texto Contexto Enferm. 2012; 21(4):870-8.

14. Corrêa AR, Andrade AC, Manzo BF, Couto DL, Duarte ED. As práticas do Cuidado Centrado na Família na perspectiva do enfermeiro da Unidade Neonatal. Esc Anna Nery. 2015; 19(4):629-34.

15. Murakami R, Campos CJG. Importância da relação interpessoal do enfermeiro com a família de crianças hospitalizadas. Rev Bras Enferm. 2011; 64(2):254-60.
16. Rochal RS, Lúcio IML, Lopes MMCO, Lima CRC, Freitas ASF. Promoção do cuidado humanizado à família pela equipe de enfermagem na unidade neonatal. Rev Rene. 2011; 12(3):502-9.

17. Silveira A, Neves ET, Zamberlan KC, Pereira FP, Arrué AM, Pieszak GM. A família de crianças/ adolescentes hospitalizados: o grupo como estratégia de cuidado. Cienc Cuid Saúde. 2012; 11(2):402-7. 